\title{
Assessing the determination of salivary electrolytes and anti-Ro and anti-La antibodies for the diagnosis of Sjögren's Syndrome (SS)
}

\author{
Beatriz Busamia ${ }^{1}$, Miguel-Angel Gonzalez-Moles ${ }^{3}$, Marcelo Mazzeo ${ }^{1}$, Jorge Linares ${ }^{1}$, Marcela Demarchi ${ }^{2}$, \\ Carla Gobbi ${ }^{2}$, Eduardo Albiero ${ }^{2}$, Ana Finkelberg ${ }^{1}$
}

${ }^{1}$ Chair of Physiology, Faculty of Dentistry, National University of Cordoba. Argentina

${ }^{2}$ Rheumatology Service. Hospital Córdoba - Sanatorium Allende. Cordoba, Argentina

${ }^{3}$ Department of Stomatology. University of Granada. Spain

Correspondence:

Cátedra de Fisiología

Facultad de Odontología

Ciudad Universitaria.

Córdoba. Argentina

beabusamia@hotmail.com.

Received: 23/03/2009

Accepted: 28/11/2009

\author{
Busamia B, Gonzalez-Moles MA, Mazzeo M, Linares J, Demarchi M, \\ Gobbi C, Albiero E, Finkelberg A. Assessing the determination of sali- \\ vary electrolytes and anti-Ro and anti-La antibodies for the diagnosis of \\ Sjögren's Syndrome (SS). Med Oral Patol Oral Cir Bucal. 2010 May 1;15 \\ (3):e437-40. \\ http://www.medicinaoral.com/medoralfree 01/v15i3/medoralv15i3p437.pdf \\ Article Number: $2771 \quad$ http://www.medicinaoral.com/ \\ (C) Medicina Oral S. L. C.I.F. B 96689336 - pISSN 1698-4447 - eISSN: 1698-6946 \\ eMail: medicina@medicinaoral.com \\ Indexed in: \\ -SCI EXPANDED \\ -JOURNAL CITATION REPORTS \\ -Index Medicus / MEDLINE / PubMed \\ -EMBASE, Excerpta Medica \\ -SCOPUS \\ -Indice Médico Españo
}

\begin{abstract}
The aim of this study was to assess changes in salivary electrolyte flow and composition and the presence of anti-Ro/SSA and anti-La/SSB serum and saliva antibodies and their implications for the non-invasive diagnosis of SS.

Study design: 73 patients were studied, divided into the following experimental groups: primary Sjögren syndrome (SSp) ( $\mathrm{n}=15)$, secondary SS (SSs) ( $\mathrm{n}=17)$, dry mouth, dry eye without Sjögren's syndrome (BO) $(\mathrm{n}=20)$ and healthy controls $(\mathrm{C})(\mathrm{n}=21)$. We conducted a baseline assessment of salivary flow and saliva sampling for the measurement of sodium, chlorine, potassium, calcium and phosphate electrolytes, and the determination of anti$\mathrm{Ro} / \mathrm{SSA}$ and La/SSB antibodies; a serum sampling was made to assess antibody positivity.

Results: Salivary flow in SSp, SSs and BO was significantly lower $(\mathrm{p}<0.001)$ relative to C. The salivary composition of SS showed an increase of inorganic components. Anti-Ro/SSA and anti-La/SSB antibodies occurred more frequently in serum and saliva in SS patients compared with BO and C, with higher frequency of positivity in serum compared with saliva.

Conclusion: Our results suggest new tools that could aid the non-traumatic diagnosis of the origin of hyposalivation.
\end{abstract}

Key words: Salivary electrolytes, ro and la antibodies, Sjögren's Syndrome, xerostomia. 


\section{Introduction}

One of the essential components for maintaining oral health is saliva, so the decline of its secretion is a major health problem of the oral tissues (1). It has been shown that saliva is able to control infections such as oral herpes thanks to its immunological function (2), and it is also involved in adequate swallowing, chewing, phonation, perception of taste, and so on. (3). Xerostomia is one of the most common stomatological symptoms (4) and among its consequences are insomnia, irritability, depression and impaired quality of life for patients. Dry mouth can be single or multi-factorial in origin, with hormonal changes, autoimmune diseases, drug intake, nutritional deficiencies, inflammatory processes, advanced age, etc. being involved in its appearance. (5). One of the most important causes of xerostomia is Sjögren's syndrome (SS), a chronic disorder that causes dry mucous membranes, mainly in mouth and eye, due to a connective tissue disorder with diminished or absent glandular secretions $(6,7)$. Currently, one of the items that lead to accurate diagnosis of the disease is derived from biopsies of minor glands of the lip, which is an invasive technique (7). Sialochemistry methods could provide a diagnostic option of great clinical interest because these are not invasive, are low cost and may well serve as a means of early diagnosis.

The aim of this study was to analyze the rates of salivary electrolytes and frequency of positive anti-Ro/SSA and $\mathrm{La} / \mathrm{SSB}$ antibodies in patients with hyposalivation of different etiology, assessing their value as a method of early diagnosis of SS syndrome.

\section{Material and Methods}

\section{Patients}

A total of 74 patients were analyzed, 32 with SS (15 had primary SS (SSp) and 17 secondary SS (SSs) and 20 with dry mouth and dry eye (BO), attended for the disease in the Rheumatology Unit of the Sanatorio Allende between January 2005 and January 2007, average age 50 years ( \pm 53 years), $86 \%$ of whom were women. The control group was composed of 22 healthy patients in the same age range as the cases that were seen in the same hospital. For the diagnosis of SS, the AmericanEuropean Consensus Group Criteria for Rheumatology (8) were used. Exclusion criteria were set as patients undergoing chemotherapy or radiation therapy to the craniofacial region, patients with tumors in the head and neck region, patients with psychiatric disorders, patients with metabolic disorders or drug intake, patients with Hepatitis C. Patients underwent a complete medical history and examination of the oral cavity. In all cases informed consent was obtained. The study was approved by the Ethics Committee of the Sanatorio Allende (CLEIS), following the guidelines of the International Medical Association.

\section{Methods}

In all patients, after rinsing with distilled water, baseline saliva samples were collected for 10 minutes in the morning, fasting, and were weighed in a precision balance (Mettler), determining a flow value using the milligram equivalent formula at milliliter per minute, dividing this value by 10 and thereby obtaining the flow in milliliters per minute. The samples were stored at $4^{\circ} \mathrm{C}$. Biochemical analysis of the inorganic compounds sodium $(\mathrm{Na}+)$, chlorine $(\mathrm{Cl}-)$ and potassium $(\mathrm{K})$ by flame photometry; calcium $(\mathrm{Ca}++)$ was performed by Henry's direct colorimetric method, and of phosphate (PO2-) by Vanderline's colorimetric technique. Venous blood collection was performed to determine anti-Ro/SSA and La/SSB antibodies, also assessed in saliva. The detection of these antibodies was made by a commercial enzyme immuno-assay (Orgentec from Germany). Plates were used that were previously immunized with SS-A and SS-B antigens. The samples were diluted 1:100 in Tris buffer, NaN3 $(0.1 \%(w / w)$ and incubated with antigen. Subsequently, nonspecific serum components were removed by washing (PBS, NaN3 0.1\% w/w). Human anti-IgG Ro and anti-IgA La antibodies were used conjugated with peroxidase; the measurement was performed in an ELISA reader. Samples from patients with optical density values higher than the standards were considered positive (the average of the optical densities of normal saliva +2 standard deviations sets the ceiling value above which a saliva problem is considered positive) (9).

\section{Statistical Analysis}

Statistical analysis was made using the Student's T-test for independent data, determining a value of $p<0.05$ to consider a comparison as statistically significant.

\section{Results}

Of the total of patients, 73 (86\%) were women, with average age of 53 and mean disease evolution of 9 years. Salivary flow values were $0.36 \pm 0.05 \mathrm{ml} / \mathrm{min}$ in the BO group, $0.22 \pm 0.003$ in SSp, $0.32 \pm 0.05$ in SSs and 1.04 \pm 0.1 in group $\mathrm{C}$. When comparing the groups studied, there was a significant decrease $(p<0.001)$ of baseline flow in patients with $\mathrm{BO}, \mathrm{SSp}$ and $\mathrm{SSs}$ in relation to group C. The SSp group presented a baseline flow value significantly lower $(p<0.05)$ than SSs and BO. The average values of the electrolytes found in saliva with their statistical differences are shown in (Table 1). Table 2 shows the percentage of cases positive for anti-Ro/ SSA and La/SSB antibodies in serum and saliva in the different experimental groups.

When making statistical comparisons between the different study groups, according to positivity for anti-Ro/ SSA and La/SSB antibodies, measured in serum and saliva, highly significant differences were observed for the Ro antibody between patients with SSp or SSs and 
Table 1. Mean values (standard error) of each electrolyte studied.

\begin{tabular}{|c|c|c|c|c|c|}
\hline Group & $\begin{array}{c}\mathrm{CL}^{-} \\
(\mathbf{m E q} / \mathrm{ml})\end{array}$ & $\begin{array}{c}\mathrm{Na}^{+} \\
(\mathbf{m E q} / \mathbf{m l})\end{array}$ & $\begin{array}{c}\mathrm{Ca}^{+2} \\
(\mathbf{m g} / \mathbf{d l})\end{array}$ & $\begin{array}{c}\mathbf{K}^{+} \\
\mathbf{m E q} / \mathbf{l})\end{array}$ & $\begin{array}{c}\mathrm{PO}^{2} \\
(\mathbf{m g} / \mathbf{d l})\end{array}$ \\
\hline $\mathrm{SSp}$ & $37.1 \pm 2.0$ & $7.07 \pm 0.5$ & $5.04 \pm 0.5$ & $23.3 \pm 2.0$ & $9.90 \pm 0.3$ \\
\hline SSs & $77.2 \pm 2.5^{(* *)}$ & $9.8 \pm 1.1^{(* *)}$ & $4.35 \pm 0.6^{(* *)}$ & $33.8 \pm 3.1^{(* *)}$ & $24.9 \pm 2.0^{(* *)}$ \\
\hline BO & $25.8 \pm 2.1^{(* *)}$ & $10.20 \pm 1.7^{(* *)}$ & $4.25 \pm 0.5^{(* *)}$ & $36.2 \pm 2.8^{(* *)}$ & $17.4 \pm 1.4^{(* *)}$ \\
\hline Control & $15.6 \pm 1.4\left(^{*}\right)$ & $8.3 \pm 1.01\left(^{*}\right)$ & $2.60 \pm 0.2\left(^{*}\right)$ & $18.8 \pm 2.1\left(^{*}\right)$ & $14.5 \pm 1.4\left(^{*}\right)$ \\
\hline
\end{tabular}

$(*)$ Indicates statistically significant differences between the control group $(\mathrm{p}<0.0001)$, and the other groups $(* *)$ Indicates statistically significant differences between the groups SSp, SSs and BO $(\mathrm{p}<0.0001) ;(* * *)$ indicates statistically significant differences between SSp and SSs $(\mathrm{p}<0.05)$. SSp: Primary Sjögren; SSs: Secondary Sjögren, BO: Dry mouth and eye; C: control.

Table 2. Percentage of samples positive for Ro and La antibodies in serum and saliva.

\begin{tabular}{|c|c|c|c|c|}
\hline \multirow{2}{*}{ Source } & \multicolumn{2}{|c|}{ SERUM } & \multicolumn{2}{c|}{ SALIVA } \\
\cline { 2 - 5 } Group & $\begin{array}{c}\text { Ro/SSB } \\
\%\end{array}$ & $\begin{array}{c}\text { La/SSB } \\
\%\end{array}$ & $\begin{array}{c}\text { Ro/SSA } \\
\%\end{array}$ & $\begin{array}{c}\text { La/SSB } \\
\text { SSp } \\
(n=17)\end{array}$ \\
78 & 70 & 55 & 46 \\
$\begin{array}{c}\text { SSs } \\
(n=15) \\
\text { BO } \\
(n=21)\end{array}$ & 70 & 65 & 48 & 40 \\
$\begin{array}{c}C \\
(n=20)\end{array}$ & 10 & 5 & 0 & 0 \\
\hline
\end{tabular}

SSp: Primary Sjogren's Syndrome, SSs: Secondary Sjögren, BO: Dry Mouth and Eye C: control.

the controls $(\mathrm{p}<0.0001)$. These differences were also observed for the antibody $\mathrm{La}(\mathrm{p}<0.0001)$.

\section{Discussion}

It is reasonable to believe that changes in salivary secretion and changes in protein composition promote the growth of microorganisms associated with the conditions most frequently found in the oral cavity (caries, gingivitis, mucosal infections) (10-12). Electrolytes are known to be secreted in the mouth by the salivary glands, although the exudation of serum from injured oral mucosa also contributes to electrolyte concentrations found in saliva. In patients with SS, an increase has been documented in the rate of salivary albumin due to inflammation of the salivary glands and to the leakage of serum through mucous membranes easily damaged by mechanical action; this could equally be the mechanism that promotes salivary electrolyte abnormalities in SS $(13,14)$.
In our control group, the concentration of electrolytes studied was within normal limits. In contrast, in the other groups of patients significant changes were observed. Although previous studies (15) have documented a slight tendency to increased salivary concentrations of Na compared with the control group, in our study we documented only a slight increase, although significant in the comparison between SSs and controls, which could be due to a decrease in Na reabsorption in the salivary gland ducts. In relation to calcium, we observed a significantly higher concentration in all groups with hyposalivation compared with the control group. In our view, increased salivary Ca stems from a shift of plasma calcium through the injured mucosa. The plasma concentration of $\mathrm{Ca}$ is a plausible source of salivary $\mathrm{Ca}$ in damaged mucosa, as previously demonstrated by Sewon et al. (14), who reported a positive correlation between gingival bleeding and $\mathrm{Ca}$ in saliva. In this study we have seen a very significant increase 
in salivary levels of $\mathrm{K}$ in all the hyposalivation groups compared with controls. Plasma $\mathrm{K}$ has a concentration about five times higher than that of salivary $\mathrm{K}$, and so mucosa altered by disorders accompanying hyposalivation could be the source of the increase in salivary $\mathrm{K}+$. The possibility might also be considered of a defect related to mechanisms of ductal reabsorption in the SS, since we have observed increased levels of $\mathrm{K}+$ in $\mathrm{SSp}$ compared to the $\mathrm{BO}$ group. With respect to phosphate concentration, the group presenting the highest rate was that of patients with SSs. However, we note that the levels increase in SSp, which is discordant since it has been shown that phosphate concentration varies inversely with salivary flow rate $(16,17)$. In all groups, differences were statistically significant in relation to controls. We did not find an explanation for observed statistical differences in rates of salivary phosphates in SSp and SSs, as there was no explanatory evidence in the literature related to the topic. However, the deepening of research on the significance of salivary phosphate in patients with hyposalivation of different origins is important for the outstanding contribution of this electrolyte in remineralization as a buffer agent in situations of low salivary flow (18). In general our findings on the salivary concentration of the electrolytes examined shows that the disorders are more pronounced in SSp and SSs compared with controls and the group BO. This could give some value to the determination of electrolytes in saliva as markers of SS.

In relation to the study of the profile of anti-Ro/SSA and La/SSB antibodies, a significant increase was seen in antibody positivity both in serum and in saliva in SSp and SSs compared with controls and with the group of patients with hyposalivation unrelated to SS. The definitive diagnosis of SS is currently made by conducting a minor salivary gland biopsy in the lip (19). Our results thus point to new tools, both through the determination of electrolytes and of Ro/SSA and La/SSB antibodies in saliva, which could help diagnose patients with hyposalivation and avoid invasive biopsy techniques. Larger studies are needed to allow further investigation of this matter.

\section{References}

1. Amerongen AV, Veerman EC. Saliva--the defender of the oral cavity. Oral Dis. 2002;8:12-22.

2. Cohen-Brown G, Ship JA. Diagnosis and treatment of salivary gland disorders. Quintessence Int. 2004;35:108-23.

3. Atkinson JC, Grisius M, Massey W. Salivary hypofunction and xerostomia: diagnosis and treatment. Dent Clin North Am. 2005;49:309-26.

4. Porter SR, Scully C, Hegarty AM. An update of the etiology and management of xerostomia. Oral Surg Oral Med Oral Pathol Oral Radiol Endod. 2004;97:28-46.

5. Ghezzi EM, Wagner-Lange LA, Schork MA, Metter EJ, Baum BJ, Streckfus CF, et al. Longitudinal influence of age, menopause, hormone replacement therapy, and other medications on parotid flow rates in healthy women. J Gerontol A Biol Sci Med Sci. 2000;55:M34-42.
6. García-Carrasco M, Fuentes-Alexandro S, Escárcega RO, Salgado G, Riebeling C, Cervera R. Pathophysiology of Sjögren's syndrome. Arch Med Res. 2006;37:921-32.

7. Mavragani CP, Moutsopoulos NM, Moutsopoulos HM. The management of Sjögren's syndrome. Nat Clin Pract Rheumatol. 2006;2:252-61.

8. Vitali C, Bombardieri S, Jonsson R, Moutsopoulos HM, Alexander EL, Carsons SE, et al. Classification criteria for Sjögren's syndrome: a revised version of the European criteria proposed by the AmericanEuropean Consensus Group. Ann Rheum Dis. 2002;61:554-8.

9. Mandel ID. The diagnostic uses of saliva. J Oral Pathol Med. 1990;19:119-25.

10. Bradshaw DJ, Marsh PD. Analysis of $\mathrm{pH}$-driven disruption of oral microbial communities in vitro. Caries Res. 1998;32:456-62.

11. Brown LR, Dreizen S, Daly TE, Drane JB, Handler S, Riggan LJ, et al. Interrelations of oral microorganisms, immunoglobulins, and dental caries following radiotherapy. J Dent Res. 1978;57:882-93.

12. Cowman RA, Baron SS, Glassman AH, Davis ME, Strosberg AM. Changes in protein composition of saliva from radiation induced xerostomia patients and its effect on growth of oral sttreptococci. J Dent Res. 1983;62:336-40.

13. Almståhl A, Wikström M, Groenink J. Lactoferrin, amylase and mucin MUC5B and their relation to the oral microflora in hyposalivation of different origins. Oral Microbiol Immunol. 2001;16:345-52.

14. Sewón LA, Karjalainen SM, Söderling E, Lapinleimu H, Simell O. Associations between salivary calcium and oral health. J Clin Periodontol. 1998;25:915-9.

15. Mandel ID. Sialochemistry in diseases and clinical situations affecting salivary glands. Crit Rev Clin Lab Sci. 1980;12:321-66.

16. Almståhl A, Wikström M. Electrolytes in stimulated whole saliva in individuals with hyposalivation of different origins. Arch Oral Biol. 2003;48:337-44.

17. Kreusser W, Heidland A, Hennemann H, Wigand ME, Knauf $\mathrm{H}$. Mono- and divalent electrolyte patterns, $\mathrm{pCO} 2$ and $\mathrm{pH}$ in relation to flow rate in normal human parotid saliva. Eur J Clin Invest. 1972;2:398-406.

18. Sule Y, Ebru T, Muge B, Ronca M, Sezen F. Comparative Analysis of Autoantibodies against alfa fodrin in Serum, Tear Fluid, and Saliva from Patients whith Sjögren's syndrome .J Rheumatol. 2006;33:289-92.

19. Margaix-Muñoz M, Bagán JV, Poveda R, Jiménez Y, Sarrión G. Sjögren's syndrome of the oral cavity. Review and update. Med Oral Patol Oral Cir Bucal. 2009;14:E325-30.

\section{Acknowledgement:}

This study was made thanks to grants from SECyT and Agencia Córdoba Ciencia. 